DOI 10.37882/2223-2974.2020.10.33

\title{
ПРАКТИЧЕСКИЕ ПОДХОДЫ К ОЦЕНКЕ НАДЕЖНОСТИ СИСТЕМЫ ВНУТРЕННЕГО КОНТРОЛЯ ДЕБИТОРСКОЙ И КРЕДИТОРСКОЙ ЗАДОЛЖЕННОСТИ В УСЛОВИЯХ ОБЕСПЕЧЕНИЯ ДОСТИЖЕНИЯ СТРАТЕГИЧЕСКИХ ЦЕЛЕВЫХ ПОКАЗАТЕЛЕЙ
}

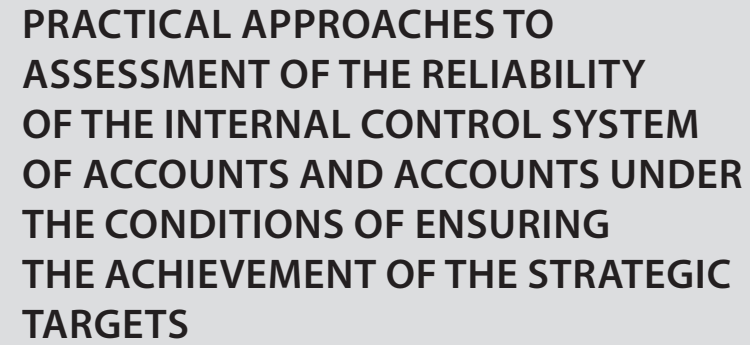

PRACTICAL APPROACHES TO

ASSESSMENT OF THE RELIABILITY

OF THE INTERNAL CONTROL SYSTEM

OF ACCOUNTS AND ACCOUNTS UNDER

THE CONDITIONS OF ENSURING

THE ACHIEVEMENT OF THE STRATEGIC

TARGETS

T. Tarasova

Summary: The article discusses the concept of internal control of an organization as a separate type of practical activity and shows how the system works in practice.

The purpose of this article is to analyze the internal control system (ICS) of receivables and payables. The objective of the article is to develop additions and improve the existing ICS at Russian Railways.

Method or methodology of work: The material of the article is presented with a focus on the risk-oriented model of internal control, since the unstable economic situation in the country and in the world directly affects both the organization's ICS and its accounting system.

Results A set of issues for the development of the theory and methodology of internal control of business processes at Russian Railways enterprises was presented, and additions to the methodological tools were developed, which ensure continuous and systematic work of the ICS. Scope of the results: This material can be used not only within the framework of transport enterprises, but also with some changes for the necessary structures, can be used by organizations of other industries in charge of, for example, cargo transportation, logistics, construction work.

Keywords: reliability assessment, accounts payable, internal control, internal audit, internal control system.

\section{Введение}

$\mathrm{P}$ иск-ориентированный подход применительно к вопросам внутреннего контроллинга является тем самым звеном в системе управления организации, которое нацелено на предотвращение возможных проблем.

CBK нацелена на результат, в частности на повыше-

\author{
Тарасова Татьяна Михайловна \\ К.э.н., дочент, Самарский государственный \\ университет путей сообщения \\ tarasova2004@inbox.ru
}

Аннотация: В статье рассмотрены понятие внутреннего контроля организации как отдельного вида практической деятельности и показано как работает система на практике.

Целью данной статьи является анализ системы внутреннего контроля (СВК) дебиторской и кредиторской задолженности. Задача статьи - разработка дополнений и усовершенствование существующей СВК в ОАО «РЖД».

Метод или методология проведения работы: Материал статьи представлен с ориентацией на риск-ориентированную модель внутреннего контроля, так как нестабильная экономическая ситуация в стране и в мире напрямую влияет как на СВК организации, так и на систему ее бухгалтерского учета.

Результаты Представлен комплекс вопросов развития теории и методики внутреннего контроля хозяйственных процессов предприятий ОАО «РЖД», а также разработаны дополнения к методическому инструментарию, который обеспечивает непрерывную и систематическую работу СВК.

0бласть применения результатов: Данный материал может быть использован не только в рамках транспортных предприятий, но также с некоторыми изменениями под необходимые структуры, может быть использован организациями других отраслей, курирующих, например, грузоперевозки, логистику, строительные работы.

Ключевые слова: оценка надежности, кредиторская задолженность, внутренний контроль, внутренний аудит, система внутреннего контроля.

ние финансового положения организации, повышение потенциала развития, обеспечения наибольшей эффективности деятельности. Таким образом, можно выделить четыре модуля: финансовые результаты, потенциал развития, процессы и система управления, внешнее окружение. Любые нововведения должны включать этапы: совершенствование СВК в целом; качественное информационное обеспечение СВК и взаимосвязь между контролем и другими рабочими процессами; оптимизация 
Методика оценки надежности СВК на предприятиях вагонного хозяйства

Приволжской Дирекции Инфраструктуры (ПривДИ)

\begin{tabular}{|c|c|c|c|c|}
\hline $\mathrm{N} n / \Pi$ & Вопрос & Возможные варианты ответов & Ответ & Надежность фактора \\
\hline 1 & 2 & 3 & 4 & 5 \\
\hline \multicolumn{5}{|c|}{ 1.Контрольная среда } \\
\hline 1.1 & $\begin{array}{l}\text { Соответствие организационной структуры организации } \\
\text { масштабам и характеру ее деятельности }\end{array}$ & $\begin{array}{l}\text { 1. Не соответствует } \\
\text { 2.Соответствует не в полной мере } \\
\text { 3. Соответствует }\end{array}$ & Оценка & $\begin{array}{l}1-\text { Низкая } \\
2-\text { Средняя } \\
3 \text { - Высокая }\end{array}$ \\
\hline 1.2 & $\begin{array}{l}\text { Наличие конфликта интересов, профессиональные } \\
\text { злоупотребления }\end{array}$ & $\begin{array}{l}\text { 1. Наличие по нескольким направлениям } \\
\text { 2. Наличие по одному направлению } \\
\text { 3.0тсутствует }\end{array}$ & Оценка & $\begin{array}{l}1-\text { Низкая } \\
2-\text { Средняя } \\
3 \text { - Высокая }\end{array}$ \\
\hline 1.3 & $\begin{array}{l}\text { Поддержка руководством непрерывного функциониро- } \\
\text { вания СВК }\end{array}$ & $\begin{array}{l}\text { 1. Нет } \\
\text { 2.По отдельным направлениям } \\
\text { 3. Да }\end{array}$ & Оценка & $\begin{array}{l}1-\text { Низкая } \\
2-\text { Средняя } \\
3 \text { - Высокая }\end{array}$ \\
\hline 1.4 & $\begin{array}{l}\text { Соответствие деятельности организации стратегии раз- } \\
\text { вития и общей корпоративной культуре 0АО «РЖД» }\end{array}$ & $\begin{array}{l}\text { 1.0тсутствует } \\
\text { 2. Соблюдено частично } \\
\text { 3. Соответствует полностью }\end{array}$ & Оценка & $\begin{array}{l}1 \text { - Низкая } \\
2-\text { Средняя } \\
3 \text { - Высокая }\end{array}$ \\
\hline 1.5 & Хорошо функционирующая кадровая политика & $\begin{array}{l}\text { 1.Слабый функционал } \\
\text { 2. Существуют конкретные недочёты в работе } \\
\text { 3. Полностью устраивает }\end{array}$ & Оценка & $\begin{array}{l}1-\text { Низкая } \\
2-\text { Средняя } \\
3 \text { - Высокая }\end{array}$ \\
\hline 1.6 & $\begin{array}{l}\text { Фактическое наличие должностных инструкций работни- } \\
\text { ков }\end{array}$ & $\begin{array}{l}\text { 1. Нет } \\
\text { 2. Да, но не для всех } \\
\text { 3. Да }\end{array}$ & Оценка & $\begin{array}{l}1 \text { - Низкая } \\
2-\text { Средняя } \\
3 \text { - Высокая }\end{array}$ \\
\hline \multicolumn{5}{|c|}{ 2. Система бухгалтерского учета } \\
\hline 2.1 & $\begin{array}{l}\text { Уровень квалификации сотрудников бухгалтерии (опыт, } \\
\text { образование и пр.) }\end{array}$ & $\begin{array}{l}\text { 1. Низкий уровень } \\
\text { 2. Средний уровень } \\
\text { 3. Высокий уровень }\end{array}$ & Оценка & $\begin{array}{l}1-\text { Низкая } \\
2-\text { Средняя } \\
3 \text { - Высокая }\end{array}$ \\
\hline 2.2 & Коэффициент текучести кадров в бухгалтерии & $\begin{array}{l}\text { 1. Высокий } \\
\text { 2. Средний по рынку } \\
\text { 3. Низкий }\end{array}$ & Оценка & $\begin{array}{l}1-\text { Низкая } \\
2-\text { Средняя } \\
3 \text { - Высокая }\end{array}$ \\
\hline 2.3 & Соответствие деятельности учётной политики & $\begin{array}{l}\text { 1. Нет } \\
\text { 2. Частично } \\
\text { 3. Да }\end{array}$ & Оценка & $\begin{array}{l}1 \text { - Низкая } \\
2-\text { Средняя } \\
3 \text { - Высокая }\end{array}$ \\
\hline 2.4 & $\begin{array}{l}\text { Инвентаризация проводится вовремя и в соответствии с } \\
\text { порядком }\end{array}$ & $\begin{array}{l}\text { 1. Нет } \\
\text { 2. Существуют ошибки объектов } \\
\text { 3. Да }\end{array}$ & Оценка & $\begin{array}{l}\text { 1- Низкая } \\
2-\text { Средняя } \\
3-\text { Высокая }\end{array}$ \\
\hline 2.5 & Соответствие деятельности графику документооборота & $\begin{array}{l}\text { 1. Нет } \\
\text { 2. Частично } \\
\text { 3. Да }\end{array}$ & Оценка & $\begin{array}{l}1-\text { Низкая } \\
2-\text { Средняя } \\
3-\text { Высокая } \\
\end{array}$ \\
\hline 2.6 & Сотрудники соответствуют должностным инструкциям & $\begin{array}{l}\text { 1. Нет } \\
\text { 2. Частично } \\
\text { 3. Да } \\
\end{array}$ & Оценка & $\begin{array}{l}1 \text { - Низкая } \\
2-\text { Средняя } \\
3-\text { Высокая } \\
\end{array}$ \\
\hline 2.7 & $\begin{array}{l}\text { Степень полноты раскрытия в учетной политике методов и } \\
\text { способов ведения учета и формирования отчетности }\end{array}$ & $\begin{array}{l}\text { 1. Низкая (не раскрыты) } \\
\text { 2. (редняя (раскрыты не все способы) } \\
\text { 3. Высокая (раскрыты) } \\
\end{array}$ & Оценка & $\begin{array}{l}1-\text { Низкая } \\
2-\text { Средняя } \\
3 \text { - Высокая } \\
\end{array}$ \\
\hline 2.8 & $\begin{array}{l}\text { Мониторинг изменений законодательной базы по вопро- } \\
\text { сам ведения бухгалтерского учёта }\end{array}$ & $\begin{array}{l}\text { 1. Не осуществляется } \\
\text { 2. Осуществляется не всегда } \\
\text { 3. Осуществляется непрерывно }\end{array}$ & Оценка & $\begin{array}{l}1-\text { Низкая } \\
2-\text { Средняя } \\
3 \text { - Высокая }\end{array}$ \\
\hline 2.9 & Контроль нетипичных операций & $\begin{array}{l}\text { 1. Не осуществляется } \\
\text { 2. Осуществляется не на всех уровнях } \\
\text { 3.0существляется }\end{array}$ & Оценка & $\begin{array}{l}\text { 1- Низкая } \\
2-\text { Средняя } \\
3 \text { - Высокая }\end{array}$ \\
\hline
\end{tabular}




\begin{tabular}{|c|c|c|c|c|}
\hline N $\Pi / \Pi$ & Вопрос & Возможные варианты ответов & Ответ & Надежность фактора \\
\hline 1 & 2 & 3 & 4 & 5 \\
\hline 2.10 & Соблюдение графика подготовки отчетности & $\begin{array}{l}\text { 1. Не соблюдается } \\
\text { 2.Соблюдается }\end{array}$ & Оценка & $\begin{array}{l}1-\text { Низкая } \\
2-\text { Высокая }\end{array}$ \\
\hline 2.11 & $\begin{array}{l}\text { Защита от несанкционированного доступа или порчи } \\
\text { документов, активов и пр. }\end{array}$ & $\begin{array}{l}\text { 1. Нет } \\
\text { 2. Частичная } \\
\text { 3. Да } \\
\end{array}$ & Оценка & $\begin{array}{l}1 \text { - Низкая } \\
2-\text {-редняя } \\
3-\text { Высокая }\end{array}$ \\
\hline \multicolumn{5}{|c|}{ 3. Система налогового учета } \\
\hline 3.1 & Ведение налогового учета & $\begin{array}{l}\text { 1. Нет } \\
\text { 2. Частично } \\
\text { 3. Да }\end{array}$ & Оценка & $\begin{array}{l}1-\text { Низкая } \\
2-\text { Средняя } \\
3-\text { Высокая } \\
\end{array}$ \\
\hline 3.2 & $\begin{array}{l}\text { Соответствие элементов учетной политики для налогового } \\
\text { учета требованиям законодательства }\end{array}$ & $\begin{array}{l}\text { 1. Не соответствуют } \\
\text { 2. Соответствуют не в полном объеме } \\
\text { 3. Соответствуют }\end{array}$ & Оценка & $\begin{array}{l}1-\text { Низкая } \\
2-\text { Средняя } \\
3-\text { Высокая }\end{array}$ \\
\hline 3.3 & Раскрытие основных способов ведения налогового учета & $\begin{array}{l}\text { 1.Не раскрыты } \\
\text { 2.Раскрыты не все } \\
\text { 3.Раскрыты } \\
\end{array}$ & Оценка & $\begin{array}{l}1 \text { - Низкая } \\
2-\text { Средняя } \\
3 \text { - Высокая } \\
\end{array}$ \\
\hline 3.5 & $\begin{array}{l}\text { Своевременность выполнения расчетов по налогам и } \\
\text { сборам }\end{array}$ & $\begin{array}{l}\text { 1. Нет } \\
\text { 2. Частично } \\
\text { 3. Да } \\
\end{array}$ & Оценка & $\begin{array}{l}1 \text { - Низкая } \\
2-\text { Средняя } \\
3 \text { - Высокая }\end{array}$ \\
\hline 3.4 & $\begin{array}{l}\text { Мониторинг изменений законодательной базы по вопро- } \\
\text { сам ведения налогового учёта }\end{array}$ & $\begin{array}{l}\text { 1. Не осуществляется } \\
\text { 2. Осуществляется периодически } \\
\text { 3. Осуществляется непрерывно }\end{array}$ & Оценка & $\begin{array}{l}\text { 1- Низкая } \\
2-\text { Средняя } \\
3 \text { - Высокая } \\
\end{array}$ \\
\hline \multicolumn{5}{|c|}{ 4. Средства контроля } \\
\hline 4.1 & $\begin{array}{l}\text { Меры по ограничению не санкционированного доступа к } \\
\text { активам }\end{array}$ & $\begin{array}{l}\text { 1. Не работают } \\
\text { 2. Работают }\end{array}$ & Оценка & $\begin{array}{l}\text { 1- Низкая } \\
2 \text { - Высокая }\end{array}$ \\
\hline 4.2 & $\begin{array}{l}\text { Меры по ограничению доступа к системе бухгалтерского } \\
\text { учета неуполномоченных лиц }\end{array}$ & $\begin{array}{l}\text { 1. Не работают } \\
\text { 2. Работают }\end{array}$ & Оценка & $\begin{array}{l}\text { 1- Низкая } \\
2 \text { - Высокая }\end{array}$ \\
\hline 4.3 & $\begin{array}{l}\text { Проведение инвентаризаций имущества и обязательств } \\
\text { (плановых и внезапных) }\end{array}$ & $\begin{array}{l}\text { 1. Не проводятся } \\
\text { 2. Проводятся }\end{array}$ & Оценка & $\begin{array}{l}1 \text { - Низкая } \\
2 \text { - Высокая }\end{array}$ \\
\hline 4.4 & Наличие сплошной нумерации исходящих документов & $\begin{array}{l}\text { 1. Нет } \\
\text { 2. Частичная } \\
\text { 3. Да }\end{array}$ & Оценка & $\begin{array}{l}1 \text { - Низкая } \\
2-\text { Средняя } \\
3 \text { - Высокая }\end{array}$ \\
\hline 4.5 & Подписи уполномоченных лиц на документах & $\begin{array}{l}\text { 1. Нет } \\
\text { 2. Да }\end{array}$ & Оценка & $\begin{array}{l}1 \text { - Низкая } \\
2 \text { - Высокая }\end{array}$ \\
\hline \multicolumn{3}{|c|}{ Итого (баллов) } & \multicolumn{2}{|r|}{ Сумма } \\
\hline
\end{tabular}

связей между элементами.

Целью данной статьи является анализ системы внутреннего контроля (СВК) дебиторской и кредиторской задолженности. Задача статьи - разработка дополнений и усовершенствование существующей СВК в ОАО «РЖД».

\section{Метод или методология проведения работы}

Материал статьи представлен с ориентацией на рискориентированную модель внутреннего контроля, так как нестабильная экономическая ситуация в стране и в мире напрямую влияет как на СBK организации, так и на систему ее бухгалтерского учета.

\section{Результаты и обсужление}

В деятельность предприятий вагонного хозяйства предлагается внедрение теста Методики оценки надёжности СВК. Представим первый вариант данной методики в Таблице 1.

По результатам апробации данной методики, получаем следующие результаты:

1. Эксплуатационное вагонное депо Астрахань сумма баллов - 68 из 73;

2. Эксплуатационное вагонное депо Максим Горький - сумма баллов - 66 из 73; 


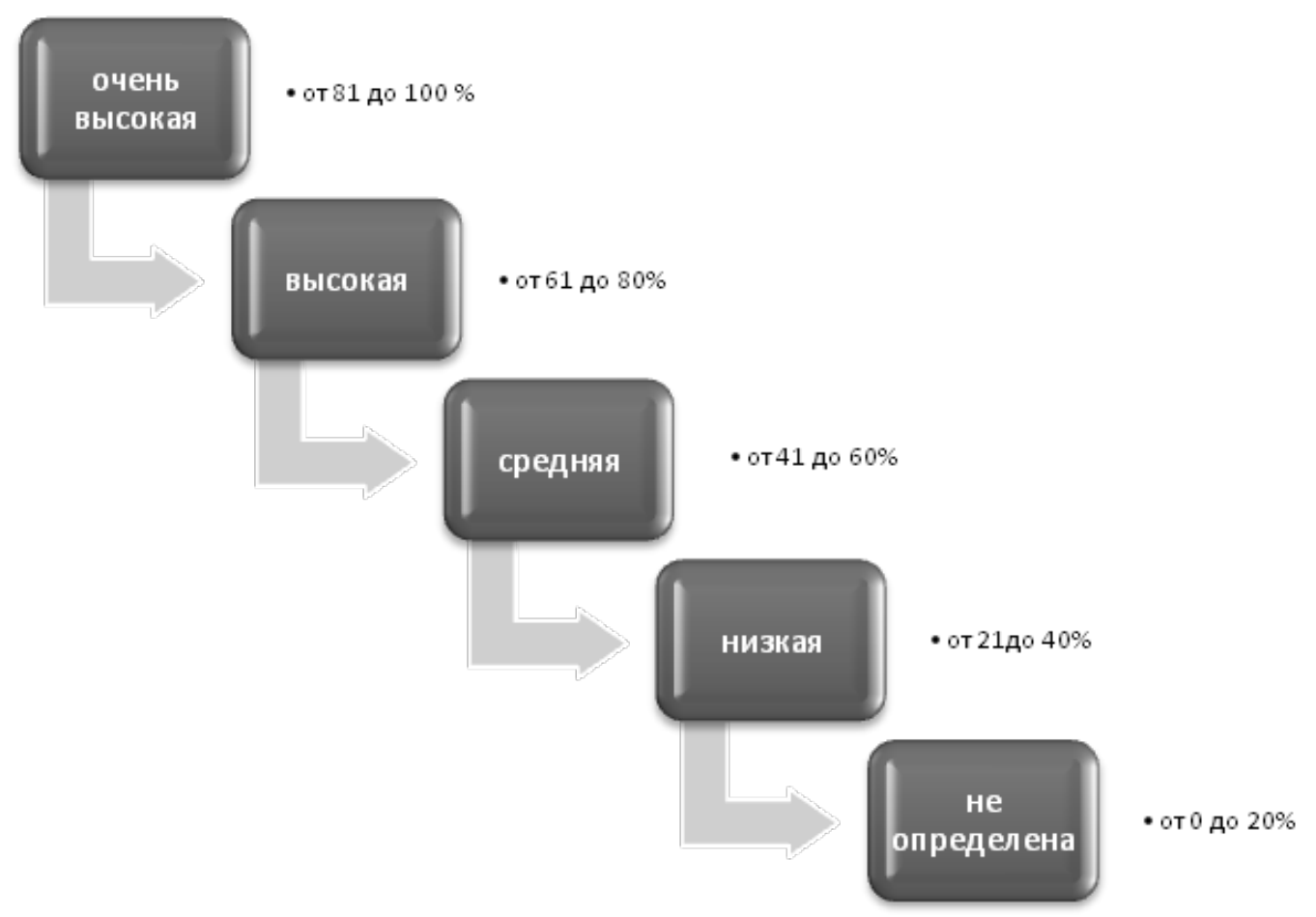

Рис. 1. Качественное определение надёжности СВК

3. Эксплуатационное вагонное депо Анисовка - сумма баллов - 63 из 73;

4. Вагонное депо Аткарск - сумма баллов - 66 из 73.

Данные цифры позволяют сделать вывод, что в целом CВК оценивается достаточно высоко. Отметим, что наименьшие баллы у всех четырёх вагонных депо получили позиции «Мониторинг изменений законодательной базы по вопросам ведения бухгалтерского учёта», «Контроль нетипичных операций» и «Мониторинг изменений законодательной базы по вопросам ведения налогового учёта».

В ходе исследования было принято решение доработать данную модель и ввести дополнительные показатели. За основу взяты некоторые показатели, предложенные в статье Замбржицкой Е.С. и Кошелевой А.Ю. [6]. В качестве дополнительных выбраны показатели 1-13 и 15, позволяющие более детально провести оценку СВК на предприятиях вагонного хозяйства Приволжской Дирекции Инфраструктуры. Также, введен дополнительный показатель «Осуществляется ли на постоянной основе мониторинг доступов сотрудников к тем или иным документам?».

По результатам подсчёта количества баллов с учётом внесённых дополнений, получаем следующие результаты:

1. Эксплуатационное вагонное депо Астрахань сумма баллов - 28 из 30;

2. Эксплуатационное вагонное депо Максим Горь-

$$
\text { кий - сумма баллов - } 28 \text { из 30; }
$$

3. Эксплуатационное вагонное депо Анисовка - сумма баллов - 27 из 30;

4. Вагонное депо Аткарск - сумма баллов - 29 из 30.

Таким образом, данная методика и дополнения к ней позволяют проводить оперативный мониторинг текущего состояния CВК, а также может выступать в качестве обратной связи между работниками бухгалтерии и СBK. Считаем целесообразным ввести данный способ обратной связи и оценки функционирования СВК. Таким образом, данное анкетирование будет проводиться раз в квартал.

Далее определим в процентах оценку фактической надёжности СВК на предприятиях ПривДИ. Для этого необходимо разделить итоговые оценки теста на максимально возможное количество баллов. Проведём расчет по формуле все результаты оформим в Таблицу 2:

$$
W=\frac{S_{1}+S_{2}}{(73+30)} * 100 \%
$$

где $W$ - значение надежности действующей СВК, в \%; $S_{1} S_{2}$ - количество баллов по тестам СВК соответственно по действующей методике и ее дополнительной части. 
Оценка надёжности действующей СВК на предприятиях ПривДИ, \%

\begin{tabular}{|l|c|}
\multicolumn{1}{|c|}{$\begin{array}{c}\text { Наименование предприятия вагонного } \\
\text { хозяйства ПривДИ }\end{array}$} & $\begin{array}{c}\text { 3начение надёжности } \\
\text { СВК, \% }\end{array}$ \\
\hline \begin{tabular}{l|} 
Эксплуатационное вагонное депо Астрахань \\
$\begin{array}{l}\text { Эксплуатационное вагонное депо Максим } \\
\text { Горький }\end{array}$
\end{tabular} \\
\hline Эксплуатационное вагонное депо Анисовка & 93 \\
\hline Вагонное депо Аткарск & 87 \\
\hline
\end{tabular}

На следующем этапе окончательного вывода о степени надёжности СBК используем шкалу, приведённую на рисунке 1.

\section{Зак^ючение}

Таким образом, текущую ситуацию оценки надёжности внутреннего контроля на предприятиях ПривДИ можем оценить по данной шкале как «очень высокая». Для себя отметим, что в данном случае эксплуатационное вагонное депо Анисовка имеет наименьшее значение надёжности (87\%) по сравнению с другими вагонными депо ПривДИ. Это значит, ПривДИ необходимо обратить внимание на некоторые недоработки и внести корректировки в текущую деятельность. Для этого необходимо ещё раз проанализировать ответы, выявить вопросы, и через некоторое время опять провести данное анкетирование с целью посмотреть динамику процесса улучшения CBK.

Кроме того, проанализированы Доклад «Контроль и аудит систем» (Security access control) - сокращённо SAC [8] и «Указание о рассмотрении структуры внутреннего контроля при аудите финансовой отчётности» (Statement on Auditing Standards 55/ 78, SAS 55/78) [7]. Данные документы так же, как и Стандарт COBIT, являются прикладными, и перед внедрением в деятельность организации нуждаются в анализе и проверке. При этом считаем целесообразным включить данные документы в обязательное ознакомление внутренним аудиторам, для изучения дополнительной информации по своей деятельности, а также с перспективой для появления новых идей усовершенствования текущей деятельности СВК ОАО «РЖД» в целом.

В Документе «Экологическая стратегия ОАО «РЖД» на период до 2017 года и перспективу до 2030 года» [9] говорится, что главной целью ОАО «РЖД» в сфере экологии является забота об экологической безопасности и здоровье людей. Однако в Документе не упомянут вопрос сбора и утилизации макулатуры. Обращаем на это внимание, так как вопрос использования, хранения, переработки (уничтожения) бумаги на данный момент стоит как никогда остро. Хотим обратить внимание, что здесь мы говорим не об организованной сдаче макулатуры и не об использовании испорченного листка в качестве черновика, а в целом о пусть частичном, но отказе от бумаги в пользу электронного носителя, насколько это возможно в настоящих условиях работы предприятий ОАО «РЖД» в целом. Например, некоторые ошибки вполне могут корректироваться электронно. В перспективе, именно информатизация сможет обеспечить дополнительную проверку отчётов контролёров, что предупредит и минимизирует ошибки.

\section{ЛИТЕРАТУРА}

1. 0 направлении Методических рекомендаций по осуществлению внутреннего финансового контроля и Методических рекомендаций по осуществлению внутреннего финансового аудита [Электронный ресурс]: Письмо Министерства финансов РФ от 19.01.2015 № 02-11-05/932 // Режим доступа: http:// www.consultant.ru/document/cons_doc_LAW_122446/, свободн. - Загл. с экрана.

2. 06 утверждении Методических рекомендаций по построению функции внутреннего аудита в холдинговых структурах с участием Российской Федерации [Электронный ресурс]: Приказ Росимущества от 03.09.2014 № 330 // Режим доступа: http://www.consultant.ru/document/cons_doc_LAW_168346/ , свободный. - Загл. с экрана.

3. Распоряжение ОАО «РЖД» от 23.01.2015 N 131р 0б утверждении Положения о системе внутреннего контроля в холдинге «РЖД» // Консультант Плюс. [Электронный ресурс] - режим доступа http://www.consultant.ru/

4. Распоряжение от 31.10.2011г. №2338р 0б утверждении Стандарта регламентов ОАО «РЖД» // Режим доступа: http://static.scbist.com/scb/ uploaded/1_1391184556.pdf, свободный. - Загл. сэкрана.

5. Учётная политика ОАО «РЖД» (в редакции приказов ОАО «РЖД» от 29.12.2017 г. № 132, от 29.12.2017 г. № 133) // Режим доступа: http://doc.rzd.ru/doc/ public/ruTRUCTURE_ID=704\&layer_id=5748\&page5748_4408=11, свободный. - Загл. с экрана.

6. Замбржицкая, Е.С. Оценка надежности системы внутреннего контроля страховой компании на уровне бизнес-процессов на примере департамента андеррайтинга / Е. С. Замбржицкая, А. Ю. Кошелева. — Текст : непосредственный // Молодой ученый. — 2016. — № 17 (121). — C. 383-389. — URL: https://moluch.ru/archive/121/33445/ (дата обращения: 12.08.2020).

7. Макаренко С.А. Методика внутреннего аудита дебиторской и кредиторской задолженности в организациях торговли [Текст] / С.А. Макаренко // Политематический сетевой электронный научный журнал Кубанского ГАУ. - 2014. - №103. - С.3-6.

8. Открытое акционерное общество «Российские железные дороги» Экологическая стратегия ОАО «РЖД» на период до 2017 года и перспективу до 2030 
года [Электронный ресурс] // Режим доступа: http://doc.rzd.ru/doc/public/ru?STRUCTURE_ID=704\&layer_id=5104\&id=6415 , свободный. - Загл. с экрана.

9. The Institute of Internal Auditors Research Foundation Proudly Presents the Systems Auditability and Control Report, Institute of Internal Auditors. Research

Foundation. Institute of Internal Auditors. Research Foundation, Price Waterhouse (Firm). The Foundation, 1991

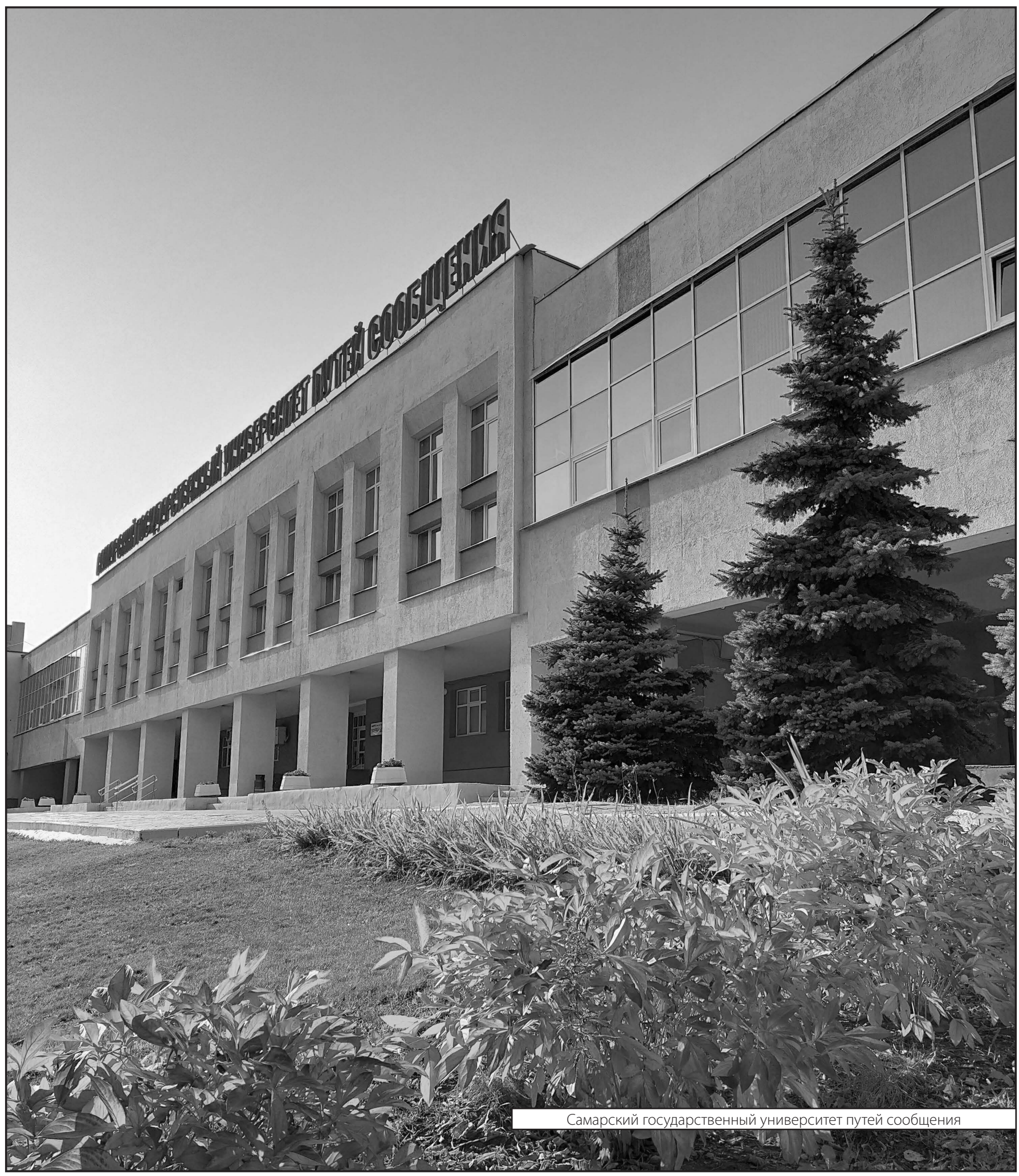

